\title{
Lamivudine-high dose interferon combination therapy for chronic hepatitis B patients co-infected with the hepatitis $\mathrm{D}$ virus
}

\author{
L. M. M. Wolters, ${ }^{1}$ A. B. van Nunen, ${ }^{1}$ P. Honkoop, ${ }^{2}$ A. C. T. M. Vossen, ${ }^{3}$ H. G. M. Niesters, ${ }^{3}$ \\ P. E. Zondervan ${ }^{4}$ and R. A. de Man $^{1}{ }^{1}$ Department of Hepatogastroenterology, Erasmus University Hospital, ${ }^{2}$ Department of \\ Internal Medicine, Ikazia Hospital, ${ }^{3}$ Department of Virology, Erasmus University Hospital and ${ }^{4}$ Department of Pathology, Erasmus University Hospital, \\ Rotterdam, the Netherlands
}

Received April 2000; accepted for publication June 2000

SUMMARY. Currently, the best option for patients with hepatitis delta is interferon alpha therapy for at least one year. To evaluate the effect of the combination lamivudinehigh-dose interferon alpha therapy, we first treated eight patients with chronic hepatitis delta infection with lamivudine for at least 24 weeks; then lamivudine was combined with a high dose of interferon alpha followed by a regular dose (9 MU tiw). Follow-up was 12 weeks. Virological, biochemical and histological features were evaluated for response to therapy. At baseline, all patients were HBsAg positive in serum and HDV RNA-(PCR)positive in plasma; HBV DNA was undetectable with the Digene Hybrid Capture assay (limit of detection $1.5 \times 10^{6} \mathrm{geq} \mathrm{ml}^{-1}$ ) in all cases. Transaminases were elevated in all patients; median ALT 68 (range 48-143) $\mathrm{IU} \mathrm{l}^{-1}$. Seven of eight patients completed the course; one patient with a pre-existing sickle cell trait was withdrawn from the trial due to the development of a nephrotic syndrome. The HBsAg-concentration in serum decreased in two out of seven patients (29\%). However, there was no significant decrease in the HBsAg-concentration in serum during treatment (median $3654 \mathrm{PEU}^{-1}$ (range 548-7684) to $5300 \mathrm{PEU} \mathrm{l}^{-1}$ (range 168-19639)). The drop of HDV RNA in plasma from baseline during treatment was not significant. Decrease of HDV RNA was observed in three out of seven patients $(43 \%)$ (median $10^{5} \mathrm{geq} \mathrm{ml}^{-1}$; range $10^{3}-10^{6}$ to median $10^{3} \mathrm{geq} \mathrm{ml}^{-1}$; range $10^{2}-10^{7}$ ). Serum ALT did not change as reflected by a median of $68 \mathrm{IU} \mathrm{l}^{-1}$ (range 48-143) at start of therapy to $63 \mathrm{IU} \mathrm{l}^{-1}$ (range 20-171) at the end of therapy. At the end of treatment transaminases had normalised in one patient and decreased in three other patients (improvement in 57\%). However, three of these four patients showed a rebound after withdrawal of therapy. The Histology Activity Index (HAI) indicated a drop from a median score of 7 (range 5-9) at baseline to 5 (range 3-8) at the end of treatment, but an increase in fibrosis from a median grade of 2 (range 1-3) at baseline to 3 (range 1-4) at the end of treatment was observed. In conclusion, this study does not yield support for the combination of an HBV suppressor and 16 weeks of high-dose interferon for therapy aimed at eradicating the hepatitis delta virus.

Keywords: chronic hepatitis B, hepatitis delta, lamivudine, interferon alpha.

\section{INTRODUCTION}

The hepatitis D virus (HDV) is a defective RNA-virus which depends on the hepatitis B virus (HBV) for replication. HDV is able to replicate in hepatocytes without the help of HBV, producing HDV RNA and HDAg, but assembly of the viral particle and survival outside hepatocytes require HBsAg. HDV infection is often severe and when it causes a super-

Abbreviations: HDV, hepatitis D virus; HBV, hepatitis B virus; IFN, interferon alpha.

Correspondence: Dr R. A. de Man, Department of Hepatogastroenterology, University Hospital Rotterdam, PO Box 2040, 3000 CA Rotterdam, The Netherlands. infection of hepatitis B, deterioration of the liver disease often occurs. Chronic hepatitis D infection leads to cirrhosis in $70 \%$ of patients [1].

The only effective treatment for HBV-infection is interferon alpha (IFN) and HBeAg-seroconversion occurs in approximately $33 \%$ of patients [2]. Lamivudine, an oral nucleoside analogue, has been shown to cause suppression of HBV DNA, a marker of active viral replication, in up to $80 \%$ of patients after 6 months of therapy [3]. Quantitative HBsAg concentrations also decreased during treatment. However, after withdrawal of this drug, an immediate rise in HBV DNA to pretreatment levels was observed followed by a more gradual increase in HBsAg concentrations [3]. 
IFN is the most promising agent for the treatment of chronic hepatitis D (HDV). Most studies stress the importance of prolonging therapy and increasing the dose, frequency and duration of administration of interferon [4-9].

A pilot study demonstrated the lack of efficacy of lamivudine monotherapy in HDV infection [10] but no data are available on the safety and efficacy of lamivudine-IFN combination therapy for patients with HDV. Therefore, we performed a pilot study in which we pretreated eight patients with lamivudine to reduce HBsAg, followed by high doses of IFN in combination with lamivudine.

\section{PATIENTS AND METHODS}

All chronic HDV-infected patients who visited the outpatient clinic of the University Hospital Rotterdam from the first of January 1996 until the first of January 1998 were considered eligible. The study was approved by the Medical Ethics Committee of the University Hospital Rotterdam.

Patients could be included in the study if they were HBsAg positive in serum and HDV RNA-positive by PCR in plasma and if the liver biopsy was positive for HDAg. ALT and AST at screening had to exceed the upper limit of normal $\left(30 \mathrm{IU} \mathrm{l}^{-1}\right)$.

All patients received $100 \mathrm{mg}$ lamivudine od for at least 24 weeks. Subsequently, IFN (Roferon, Roche) was added: first at a high dose of $9 \mathrm{MU}$ od for four weeks, followed by $9 \mathrm{MU}$ tiw for 12 weeks. Both IFN and lamivudine were withdrawn after at least 16 weeks of combination therapy. Follow-up was 12 weeks.

A liver biopsy was taken prior to the start of lamivudine therapy and at the end of combination therapy. All liver biopsies were graded according to the Histology Activity Index (HAI) using the Desmet modification of the Knodell scoring system [11,12]. The specimens were also stained immunohistochemically to detect surface antigen of the hepatitis B virus and hepatitis delta antigen, as previously described [13]. The histological diagnosis was made by two independent histopathologists according to international criteria [14].

Blood samples were drawn every four weeks during treatment and follow-up. Serum samples were stored at $-20{ }^{\circ} \mathrm{C}$ for detection of HBsAg and HBV DNA, plasma samples were stored at $-80{ }^{\circ} \mathrm{C}$ for detection of HDV RNA. Haematological parameters, markers of hepatitis activity (ALT, AST) and bilirubin levels were determined every four weeks.

HBsAg was quantified with a microparticle enzyme immunoassay (MEIA, AxSYM, Abbott) against a standard related to the HBsAg reference preparation (Paul Ehrlich Institute). HBV DNA levels were measured with a Hybrid Capture assay (Digene, Abbott, UK) quantified with the EUROHEP standard as reference and expressed in genome equivalents $\mathrm{ml}^{-1}$ (geq ml $\mathrm{l}^{-1}$ ). The limit of detection of this assay is $1.5 \times 10^{6} \mathrm{geq} \mathrm{m}^{-1}$. HBeAg was detected with the IMx-assay (Abbott, Chicago, USA). HDV RNA was quantified by means of a PCR method, as described by de Man et al. [13], with a limit of detection of $100 \mathrm{geq} \mathrm{ml}^{-1}$.

\section{Virological response to therapy}

A complete virological response was defined as disappearance of HDV RNA in serum. A partial response was defined as a reduction in HDV RNA from baseline. The decrease in HBsAg concentration in individual patients was monitored during therapy and follow-up. In the liver, a response was defined by a decrease in the number of hepatocytes with a positive stain for hepatitis B and D antigens.

\section{Biochemical response to therapy}

A complete biochemical response was defined as normalization of serum ALT, a partial response as a reduction of ALT with respect to baseline values.

\section{Histological response to therapy}

A histological response was defined by a decrease in inflammation and fibrosis.

\section{Statistical analysis}

Patients were evaluated in the per protocol analysis if they completed at least 24 weeks of lamivudine monotherapy followed by at least 16 weeks of IFN therapy, initially at high doses.

The Wilcoxon's sign rank test was used to analyse virological, biochemical and histological changes in these patients.

\section{RESULTS}

Eight patients were included in this trial. In patient 8, lamivudine and IFN were discontinued after 3 weeks of combination therapy due to a nephrotic syndrome which required hospitalization. This patient was excluded from the per protocol analysis.

Five patients were found to be negative for antibodies to the human immunodeficiency virus (HIV); anti-HIV was not determined in patients 2, 3 and 4. Seven patients were negative for antibodies against the hepatitis $\mathrm{C}$ virus $(\mathrm{HCV})$. Anti-HCV was found to be positive in patient 4; however, HCV RNA by PCR was negative in this patient.

The median age of the treated group was 38 (range 25-39) years at the start of lamivudine treatment. Patient characteristics are presented in Table 1.

Baseline characteristics are shown in Table 2. All patients were positive for HBsAg in serum. None of the patients had an active hepatitis $B$ infection, as shown by the negative hybridization assay for HBV DNA and HBeAg negativity for 
all patients. All patients were positive for HDV RNA in plasma with a positive stain of the liver biopsy for HDAg. None of the patients had cirrhosis before the start of therapy.

Table 1 Patient characteristics

\begin{tabular}{ll}
\hline Median age (range) & $38(25-41)$ \\
Sex (m/f) & $6 / 2$ \\
Route of transmission of HBV/HDV & \\
$\quad$ Intravenous drug abuse & 1 \\
Sexual & 1 \\
$\quad$ Unknown & 6 \\
Country of birth & 1 \\
The Netherlands & 4 \\
Africa & 3 \\
Middle East & 3 \\
\hline
\end{tabular}

Table 2 Baseline characteristics

\begin{tabular}{|c|c|c|c|c|c|}
\hline Patient & $\begin{array}{l}\mathrm{HBsAg}{ }^{*} \\
\left(\mathrm{PEU} \mathrm{l^{-1 }}\right)\end{array}$ & $\begin{array}{l}\text { HDV RNA } \\
\mathrm{PCR} \dagger \\
\left(\text { geq } \mathrm{ml}^{-1}\right)\end{array}$ & $\begin{array}{l}\text { ALT }+ \\
\left(\mathrm{IU} \mathrm{l} ~^{-1}\right)\end{array}$ & HAI§ & Fibrosis \\
\hline 1 & 3654 & $10^{5}$ & 51 & 7 & 2 \\
\hline 2 & 6629 & $10^{5}$ & 113 & 9 & 3 \\
\hline 3 & 548 & $10^{4}$ & 129 & 6 & 3 \\
\hline 4 & 3622 & $10^{6}$ & 68 & 5 & 1 \\
\hline 5 & 5999 & $10^{6}$ & 143 & 8 & 2 \\
\hline 6 & 736 & $10^{5}$ & 48 & 7 & 3 \\
\hline 7 & 7684 & $10^{5}$ & 65 & 5 & 1 \\
\hline 8 & 170 & $10^{4}$ & 50 & 3 & 1 \\
\hline
\end{tabular}

${ }^{*}$ Limit of detection $=0.6 \mathrm{PEU} \mathrm{l}^{-1}$.

$\dagger$ Limit of detection $=100 \mathrm{geq}^{-1}$.

+ Upper limit of normal $=30 \mathrm{IU} \mathrm{l}^{-1}$.

$\S \mathrm{HAI}=$ Histology Activity Index (range 0-18).

ฯ Range 0-4; 4 indicates cirrhosis.
The median HAI score for disease activity was 7 (range 5-9) at the start of therapy. All patients had elevated transaminase levels $(<5 \times \mathrm{ULN})$.

The following results are based on the patients included in the per protocol analysis. The median time elapsed from pretreatment biopsy to post-treatment biopsy was 15 (range 12-30) months. The median duration of lamivudine treatment before administration of IFN was 8 (range 5.5-10.5) months followed by a median period of 4 (range 4-6) months of combination therapy with IFN. Patient 4 continued on lamivudine therapy for another 6 months after withdrawal of IFN.

\section{Virological response}

There was no significant change in HDV RNA levels between the start and the end of treatment. A decrease from a median of $10^{5} \mathrm{geq} \mathrm{ml}^{-1}$ (range $10^{3}-10^{6} \mathrm{geq} \mathrm{ml}^{-1}$ ) to a median of $10^{3} \mathrm{geq} \mathrm{ml}^{-1}$ (range $10^{2}-10^{7} \mathrm{geq} \mathrm{ml}^{-1}$ ) was observed. At the end of treatment, a complete virological response with regard to HDV RNA was not found for any of the patients. A partial response was found in patients 3, 5 and 6 with a decrease in hepatitis D viral load of $1 \log$, 3log and 3log, respectively.

HBsAg increased slightly from a median of 3654 (range 548-7684) $\mathrm{PEU} \mathrm{l}^{-1}$ to 6911 (range 358-17523) at the start of IFN therapy and subsequently decreased to 5300 (range 168-19639) $\mathrm{PEU} \mathrm{l}^{-1}$ at the end of therapy. Patients 3 and 6 showed a marked decrease of $45 \%$ (at start of IFN therapy) to $69 \%$ (at the end of therapy) and $19 \%$ (at start of IFN therapy) to $54 \%$ (at the end of therapy), respectively. Patient 3 underwent a rebound after withdrawal of therapy whereas the level in patient 6 continued to decrease with respect to the end of therapy level (Table 3).

HBV DNA was not used as a marker of response to therapy, since it was suppressed below the limit of detection of the liquid hybridization assay in all cases. In four

\begin{tabular}{|c|c|c|c|c|c|c|c|}
\hline & \multicolumn{2}{|l|}{ HBsAg } & \multicolumn{2}{|c|}{ HDV RNA } & \multirow{2}{*}{$\begin{array}{l}\operatorname{ALT}\left(\mathrm{IU} \mathrm{l}^{-1}\right) \\
\mathrm{ULN}=30 \mathrm{IU} \mathrm{l}^{-1}\end{array}$} & \multirow[b]{2}{*}{ HAI } & \multirow[b]{2}{*}{ Fibrosis } \\
\hline & Serum & Liver & Serum & Liver & & & \\
\hline pt 1 & $\uparrow 45 \%$ & $\downarrow$ & $\approx$ & $\downarrow$ & $51 \rightarrow 171$ & $\downarrow(2)$ & $\uparrow(2)$ \\
\hline pt 2 & $\uparrow 196 \%$ & $\approx$ & $\uparrow 2 \log$ & $\approx$ & $13 \rightarrow 50$ & $\downarrow(4)$ & $\approx$ \\
\hline pt 3 & $\downarrow 69 \%$ & $\approx$ & $\downarrow 1 \log$ & $\downarrow$ & $129 \rightarrow 20$ & $\downarrow(3)$ & $\approx$ \\
\hline pt 4 & $\approx$ & $\downarrow$ & 个1log & $\approx$ & $68 \rightarrow 63$ & $\uparrow(3)$ & $\uparrow(1)$ \\
\hline pt 5 & $\uparrow 20 \%$ & $\approx$ & $\downarrow 3 \log$ & $\downarrow$ & $143 \rightarrow 98$ & $\approx$ & $\uparrow(1)$ \\
\hline pt 6 & $\downarrow 54 \%$ & $\approx$ & $\downarrow 3 \log$ & $\downarrow$ & $48 \rightarrow 68$ & $\downarrow(2)$ & $\downarrow(2)$ \\
\hline pt 7 & $\uparrow 96 \%$ & $\uparrow$ & $\approx$ & $\approx$ & $65 \rightarrow 53$ & $\uparrow(2)$ & $\uparrow(2)$ \\
\hline
\end{tabular}

Table 3 Per protocol analysis of response to therapy (baseline vs. end of combination therapy)

$\downarrow$, decrease; $\approx$, no change; $\uparrow$, increase; HAI, Histology Activity Index; ( ), number of points increase/decrease; ULN, Upper Limit of Normal. 
(a)
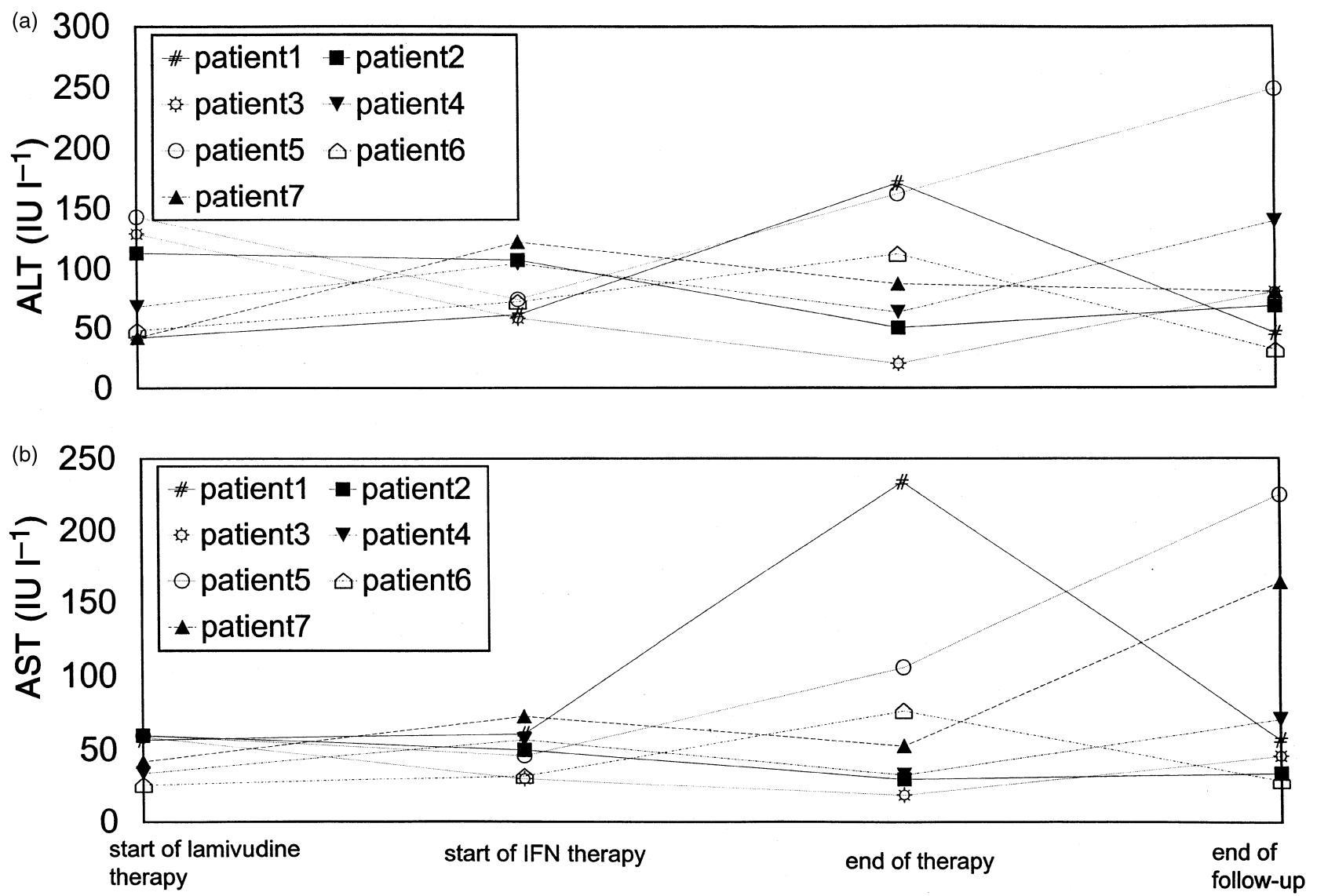

Fig. 1 Response of (a) ALT and (b) AST during therapy, individual patients. Upper limit of normal $=30 \mathrm{IU} \mathrm{l}^{-1}$.

out of seven patients HBV DNA was even suppressed below the limit of the sensitive PCR-test (limit of detection 400 geq $\mathrm{ml}^{-1}$ ).

\section{Biochemical response}

No significant change was observed between the start and the end of treatment $(P=0.499)$ (Fig. 1). Median ALT remained at the same level before, during and after therapy. The median ALT at start of lamivudine therapy was $68 \mathrm{IU} \mathrm{l}^{-1}$ (range 48-143), $74 \mathrm{IU} \mathrm{l}^{-1}$ (range 44-107) at the moment of addition of IFN therapy, $63 \mathrm{IU} \mathrm{l}^{-1}$ (range 20-171) at the end of therapy and $68 \mathrm{IU} \mathrm{l}^{-1}$ (range 19-293) at the end of follow-up. Patient 3 exhibited a complete biochemical response, combined with a decrease in HDV RNA and HBsAg (Fig. 2). Patients 2, 5 and 7 showed a partial response with a decrease in transaminase levels from 113, 143 and $65 \mathrm{IU} \mathrm{l}^{-1}$ at the start of therapy to 50, 98, $53 \mathrm{IU} \mathrm{l}^{-1}$ at the end of treatment, respectively. However, in three patients, including the patient with a complete response, a rebound occurred during follow-up. ALT remained at the same level or increased during treatment in the other three patients (Table 3).

\section{Histology}

Comparison of biopsies taken at the start and the end of treatment revealed an improvement in the overall HAI-score from a median of 7 (range 5-9) to 5 (range 3-8) $(P=0.395$, n.s.). There was an increase in the median rate of fibrosis from grade 2 (range 1-3) at the start of treatment to grade 3 (range 1-4) at the end of treatment $(P=0.334$, n.s). Two patients developed cirrhosis during treatment. Staining of biopsies for HBsAg showed a drop in the median from 5\% (range $0-50 \%$ ) to $1 \%$ (range $0-30 \%$ ). HDAg staining was minimal in all cases, both at the start (median $1 \%$, range $1-10 \%$ ) and at the end of therapy (median $1 \%$, range $0-1 \%$ ) (Table 3).

\section{Adverse events}

Combination therapy was discontinued for patient 8 due to a nephrotic syndrome. After 3 weeks of high dose IFN, this patient had to be hospitalised. The patient had already been diagnosed with a $\beta$-thalassaemia, a heterozygous sickle cell trait and hypertension. A kidney biopsy showed sclerosis of the glomeruli, caused by ischaemic damage induced by 


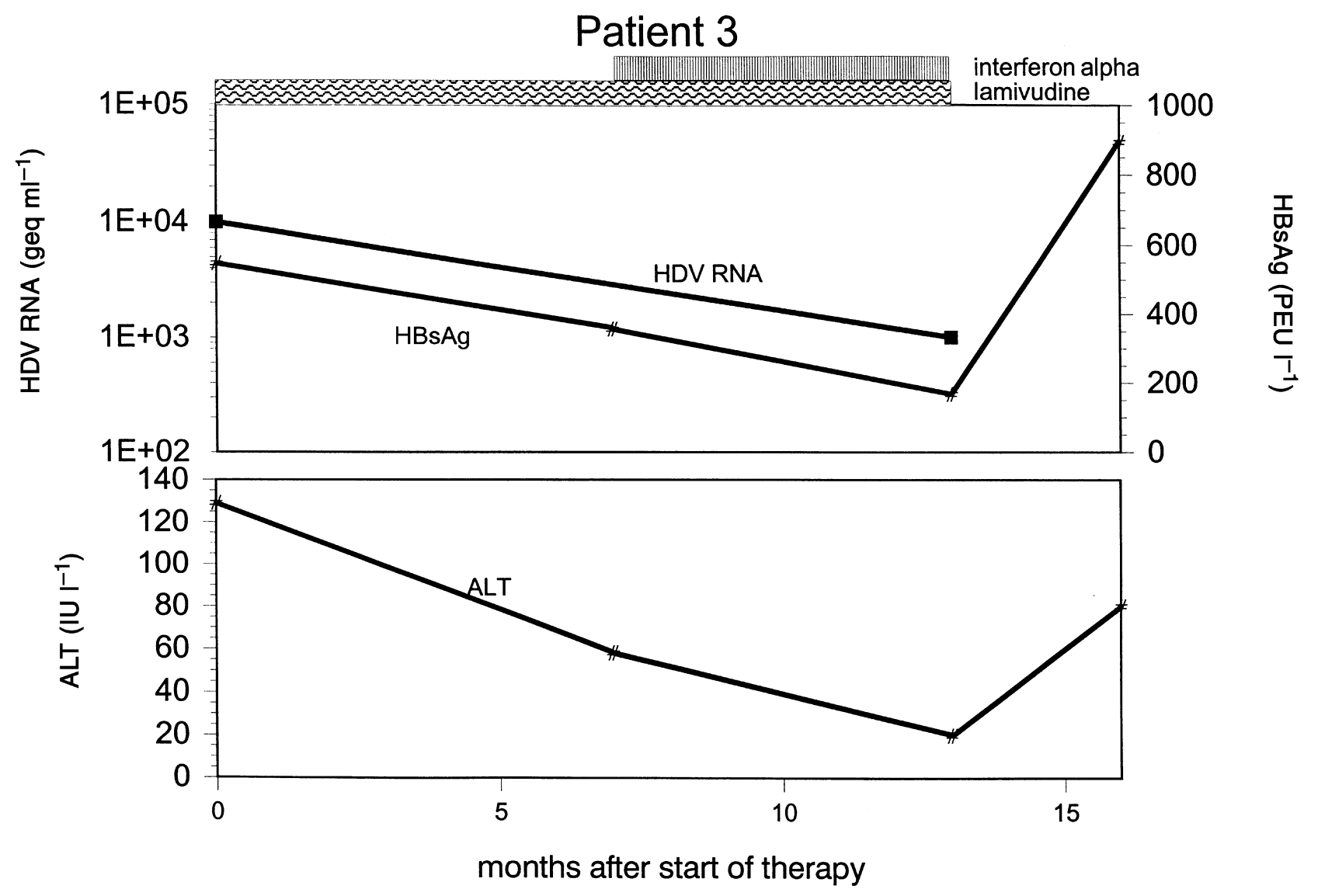

Fig. 2 Response of HBsAg, HDV RNA and ALT during therapy in patient 3 who exhibited a decrease in viral load.

sickle cell crises in the past. Moreover, necrosis of tubuli was observed, probably caused by IFN. After withdrawal of both lamivudine and IFN, renal function improved as did the clinical signs. This case resembles previous case reports on renal toxicity due to the use of IFN $[15,16]$.

Lamivudine monotherapy was well tolerated. Five of seven patients experienced mild side-effects during lamivudine-IFN combination therapy, related to the IFN (flu-like symptoms, hair loss, fatigue).

\section{DISCUSSION}

Since chronic hepatitis D patients are at high risk of developing liver cirrhosis, they are in need of effective antiviral therapy to prevent liver decompensation. In our study, we combined our knowledge about lamivudine treatment for chronic hepatitis B patients and IFN therapy for chronic hepatitis delta patients. This resulted in initially high-dose IFN treatment combined with a suppressor of active replication of the hepatitis B virus: lamivudine.

The focus of this treatment was the virological response to therapy as shown by changes in quantitative HDV RNA and quantitative HBsAg, the biochemical response as shown by changes in ALT and the possible histological improvement.
No significant changes in HDV RNA were seen in response to treatment, nor did any of the patients show a complete virological response. However, a decrease was seen in three out of seven patients. This observation does not show the same results as a study published by Farci et al. [9] in which high-dose IFN (9 MU tiw) during 48 weeks caused a complete virological response in the majority of patients at the end of treatment. The poorer results can at least partly be explained by the considerable shorter treatment period applied in our study. Studies in which patients were treated with induction of IFN followed by lower doses during one year, have produced inconsistent results. A multicentre Italian trial did not show a significantly stronger suppression of HDV RNA compared to the placebo [4], whereas a French trial showed a complete response of HDV RNA at the end of treatment in seven out of nine treated patients [5]. The differences as seen in these trials might have been caused by the different ethnic backgrounds of those patients infected with more susceptible strands of virus or because of the shorter duration of infection at the start of treatment.

Since HDV is said to disappear from serum after HBsAg seroconversion [17], HBV as a prerequisite for HDV survival should be the main focus of treatment. 
HBsAg did not change significantly during treatment of our patients. A reduction was observed in two patients which coincided with a normalization of ALT in one patient and a decrease in ALT in the other patient. In the patient with a complete biochemical response, HDV RNA in plasma, HDAg in the liver and the HAI score decreased as well. Lamivudine as therapy for chronic hepatitis B monoinfection has been studied extensively and has proved to be a suppressor of $\mathrm{HBV}$ DNA [3,18,19]; also, a reduction of HBsAg which followed the decrease in HBV DNA was observed during a 6-month treatment period [3]. A recent study in which five hepatitis delta patients were treated with lamivudine for 52 weeks and followed for 6 months after withdrawal of therapy showed a decrease in HBsAg and HDV RNA PCR in only one HBeAg positive patient. No improvement was seen in either liver histology or serum transaminase activity [10]. Lamivudine is a suppressor of reverse transcription from a positive RNA strand to - in the case of the hepatitis B virus - a negative DNA strand. The hepatitis D virus, however, is a negative RNA virus which replicates without reverse transcription. Moreover, the hepatitis D virus is dependent on cellular polymerases, probably RNA polymerase II, for replication. Lamivudine has little effect on $\alpha$-, $\beta$ - and $\gamma$-polymerases of mammalian cells. Therefore, it is not to be expected that lamivudine would have any effect on replication of the hepatitis D virus. As a result, lamivudine could only have an indirect effect on the hepatitis D virus by reducing HBsAg. As can be observed in our patient group, reduction of HBsAg in serum in two patients coincided with a reduction of HDV RNA in plasma in both patients.

A complete biochemical response was observed in one patient and a partial response was seen in three patients at the end of treatment. However, IFN treatment for up to one year caused normalization of transaminases in the majority of patients when higher doses were given [9]. As described during lamivudine therapy for chronic hepatitis B, inflammation was reduced during a 6-month treatment period. In these patients, the decrease in transaminases followed a decrease in HBV DNA as marker of active viral replication. As shown by Lai et al. [19], lamivudine therapy for chronic hepatitis $\mathrm{B}$ patients caused normalization of ALT in the majority of cases after one year of treatment compared to the placebo group. In the patients in our study, however, the hepatitis B virus was suppressed, as shown by HBeAg negativity and HBV DNA negativity by PCR in four out of seven patients and by liquid hybridization assay in the other three patients. As described by others [20], the inactivity of the hepatitis B virus is probably caused by the hepatitis D virus.

The low level of hepatitis B replication suggests that the elevation of transaminases seen in all patients at the start of therapy was probably caused by the hepatitis D virus. The relatively mild inflammation observed in these patients at the start of therapy contradicts data published by others $[4,5,9]$. One reason for this less severe inflammation could be that these patients, predominantly originating from African countries, were infected with less virulent genotypes [21]. Furthermore, a fluctuating course of the disease should be taken into consideration: most of our patients may have been in a relatively quiet phase at the moment of entry. Moreover, these patients could have suffered from a more advanced disease in which a more stable, lower level of inflammation, reflected in slightly increased transaminases, was achieved.

A two-point, not significant, drop in HAI was observed. In contrast, an increase in fibrosis occurred. Changes in the number of hepatocytes infected with virus, as indicated by staining of hepatitis $\mathrm{B}$ and $\mathrm{D}$ antigens, were ambiguous. In addition, disappearance of HDAg staining in three patients contrasted with HDV RNA in plasma, which was still detectable. The absence of HDAg in the liver might have been caused by sampling, with relatively few hepatocytes expressing delta antigen.

Although some patients experienced a short-term decrease in viral load and/or ALT, a complete virological response in combination with a complete biochemical response was not observed.

In conclusion, neither lamivudine alone nor the addition of initially high-dose IFN was capable of significantly reducing HDV RNA, HBsAg, serum transaminases or histology. On the basis of our data we cannot recommend lamivudine-IFN combination therapy for chronic HDV infection.

\section{ACKNOWLEDGEMENT}

The authors thank Prof. Dr S.W. Schalm for his careful review of the article.

\section{REFERENCES}

1 Rizetto M, Hoyer B, Purcell R, Gerin J. Hepatitis delta virus infection. In: Vyas G, Dienstag J, Hoofnagle J, eds. Viral Hepatitis and Liver Disease. New York: Grune \& Stratton, 1984: 371-377.

2 Wong DK, Cheung AM, O'Rourke K, Naylor CD, Detsky AS, Heathcote J. Effect of alpha-interferon treatment in patients with hepatitis Be antigen-positive chronic hepatitis B. A meta-analysis. Ann Intern Med 1993; 119: 312-323.

3 Nevens F, Main J, Honkoop P et al. Lamivudine therapy for chronic hepatitis B: a six-month randomized dose ranging study. Gastroenterology 1997; 113: 1258-1263.

4 Rosina F, Pintus C, Meschievitz C, Rizzetto M. A randomized controlled trial of a 12-month course of recombinant human interferon-alpha in chronic delta (type D) hepatitis: a multicenter Italian study. Hepatology 1991; 13: 1052-1056.

5 Gaudin JL, Faure P, Godinot H, Gerard F, Trepo C. The French experience of treatment of chronic type D hepatitis with a 12-month course of interferon alpha-2B. Results of a randomized controlled trial. Liver 1995; 15: 45-52.

6 Lau JY, King R, Tibbs CJ et al. Loss of HBsAg with interferonalpha therapy in chronic hepatitis D virus infection. J Med Virol 1993; 39: 292-296. 
7 Porres JC, Carreño V, Bartolomé J, Moreno A, Galiana F, Quiroga JA. Treatment of chronic delta infection with recombinant human interferon alpha $2 \mathrm{c}$ at high doses. J Hepatol, 1989; 9: 338-344.

8 Madejón A, Cotonat T, Bartolomé J, Castillo I, Carreño V. Treatment of chronic hepatitis D virus infection with low and high doses of interferon-alpha 2a: utility of polymerase chain reaction in monitoring antiviral response. Hepatology 1994; 19: 1331-1336.

9 Farci P, Mandas A, Coiana A et al. Treatment of chronic hepatitis D with interferon alfa-2a. N Engl J Med 1994; 330: 88-94.

10 Lau DT-Y, Doo E, Park Y et al. Lamivudine for chronic delta hepatitis. Hepatology 1999; 30: 546-549.

11 Knodell RG, Ishak KG, Black WC et al. Formulation and application of a numerical scoring system for assessing histological activity in asymptomatic chronic active hepatitis. Hepatology 1981; 1: 431-435.

12 Desmet VJ, Gerber M, Hoofnagle JA, Manns M, Scheuer PJ. Classification of chronic hepatitis: diagnosis, grading and staging. Hepatology 1994; 19: 1513-1520.

13 Man RA, Sprey RP, Niesters HG et al. Survival and complications in a cohort of patients with anti-delta positive liver disease presenting in a tertiary referral clinic. J Hepatol 1995; 23: 662-667.

14 Schlichting P, Fauerholt L, Christensen E, Poulsen H, Juhl E, Tygstrup N. Clinical relevance of restrictive morphological criteria for the diagnosis of cirrhosis in liver biopsies. Liver 1981; 1: 56-61.

15 Nassar GM, Pedro P, Remmers RE, Mohanty LB, Smith W. Reversible renal failure in a patient with the hypereosinophilia syndrome during therapy with alpha interferon. Am J Kidney Dis 1998; 31: 121-126.

16 Shah M, Jenis EH, Mookerjee BK et al. Interferon-alphaassociated focal segmental glomerulosclerosis with massive proteinuria in patients with chronic myeloid leukemia following high dose chemotherapy. Cancer 1998; 83: 1938-1946.

17 Battegay M, Simpson LH, Hoofnagle JH, Sallie R, Di Bisceglie AM. Elimination of hepatitis delta virus infection after loss of hepatitis B surface antigen in patients with chronic delta hepatitis. J Med Virol 1994; 44: 389-392.

18 Dienstag JL, Perrillo RP, Schiffs ER, Bartholomew M, Vicary C, Rubin M. A preliminary trial of lamivudine for chronic hepatitis B infection. N Engl J Med 1995; 333: 1657-1661.

19 Lai CL, Chien RN, Leung NW et al. A one-year trial of lamivudine for chronic hepatitis B. N Engl J Med 1998; 339: 61-68.

20 Hadziyannis SJ, Sherman M, Lieberman HM, Shafritz DA. Liver disease activity and hepatitis $\mathrm{B}$ virus replication in chronic delta antigen-positive hepatitis B virus carriers. Hepatology 1985; 5: 544-547.

21 Hadziyannis S. Delta hepatitis. J Gastroenterol Hepatol 1997; 12: 289-298. 